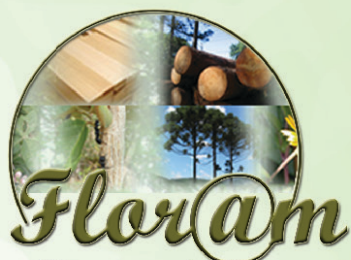

Floresta e Ambiente
Floresta e Ambiente 2016; 23(2): 211-219

http://dx.doi.org/10.1590/2179-8087.104914

ISSN 2179-8087 (online)

\title{
Análise Econômica e de Sensibilidade em um Povoamento Implantado no Sudoeste da Bahia
}

\author{
Aline Pereira das Virgens ${ }^{1}$, Luis Carlos de Freitas ${ }^{1}$, Ângelo Márcio Pinto Leite ${ }^{2}$ \\ ${ }^{1}$ Departamento de Fitotecnia e Zootecnia, Universidade Estadual do Sudoeste da Bahia - UESB, \\ Vitória da Conquista/BA, Brasil \\ ${ }^{2}$ Departamento de Engenharia Florestal, Universidade Federal do Vale do Jequitinhonha e Mucuri - UFVJM, \\ Diamantina/MG, Brasil
}

\begin{abstract}
RESUMO
A execução de um projeto florestal deve ser norteada por ferramentas de análise econômica, de forma que se possa respaldar os investimentos realizados. Objetivou-se neste trabalho promover uma análise econômica e de sensibilidade em projetos de reflorestamento de eucalipto na microrregião de Vitória da Conquista, BA. Utilizou-se como critério o Valor Presente Líquido, a Taxa Interna de Retorno, o Valor Periódico Equivalente e o Custo Médio de Produção. A análise de sensibilidade foi realizada através da variação da taxa anual de juros, da produção e do preço da madeira. O custo de implantação apresentou valor de 2.091,92 reais/ha. Se tratando do processo de condução, obteve-se um valor de 915,29 reais/ha, corrigidos para o ano zero. Apesar da característica de longo prazo, a atividade florestal constituiu alternativa de renda para os pequenos produtores, apresentando viabilidade econômica em todos os critérios avaliados.
\end{abstract}

Palavras-chave: projetos florestais, critérios de avaliação econômica, custos e receitas de reflorestamento.

\section{Economic and Sensitivity Analysis in a Settlement Stablished in Southwestern Bahia}

\begin{abstract}
The implementation of a forestry project should be guided by tools of economic analysis in order to endorse investments made. This work aimed to promote an economic and sensitivity analysis of eucalyptus reforestation projects in the microregionof Vitoria da Conquista - BA, using the Net Present Value, Internal Rate of Return, Journal Equivalent Value and Production Average Cost as well as to perform a sensitivity analysis, by varying the production annual interest rate and the price of wood. The implementation cost was $\$ 2,091.92$ reais. Tconsideration of the execution process yielded a value of $\$ 915.29$ reais, corrected for the year zero. Despite being long-term process, forestry activities are a good alternative to diversify production and income for small producers, presenting an economic viability for all criteria evaluated.
\end{abstract}

Keywords: forest projects, economic evaluation criteria, costs and revenues of reforestation. 


\section{INTRODUÇÃO E OBJETIVOS}

Atualmente, o segmento florestal vem conquistando espaço no cenário nacional: a área plantada de 7,74 milhões de hectares responde por $91 \%$ de toda a madeira produzida para fins industriais no país. A participação do setor de árvores plantadas no PIB brasileiro tem crescido a cada ano, representando em 2014 1,1\% de toda a riqueza gerada no Brasil e 5,5\% do PIB industrial. Apesar de ocupar um percentual de apenas $0,9 \%$ do território nacional, as florestas plantadas apresentam grande contribuição na construção de uma economia verde, por as empresas do setor estarem comprometidas com a utilização das melhores práticas socioambientais (IBÁ, 2015). Essa contribuição tem-se revelado de notável relevância na geração de produtos, tributos, empregos e renda. Pode-se dizer que o setor é estratégico no fornecimento de matéria-prima para o desenvolvimento da indústria de base florestal.

Em 2013, a receita bruta do regime florestal totalizou $\mathrm{R} \$ 56$ bilhões, representando 5,5\% do Produto Interno Bruto (PIB) Industrial; as exportações somaram cerca de US\$ 8 bilhões, o equivalente a 3\% das exportações brasileiras; o setor de árvores plantadas também foi responsável por 5 milhões de empregos diretos, indiretos e resultantes do efeito renda, beneficiando aproximadamente $5 \%$ da população brasileira economicamente ativa (IBÁ, 2015).

Em relação ao Estado da Bahia, plantios florestais totalizaram $671 \mathrm{mil}$ hectares, apresentando um crescimento de 6,3\% em relação a 2013. Esse total corresponde a apenas $1,2 \%$ do território baiano, com destaque para as regiões sul, sudoeste, oeste e do litoral norte do estado. Ocupa atualmente o quinto lugar no ranking dos principais estados produtores de florestas no Brasil, representando 8,7\% da área plantada total do país (ABAF, 2015).

A execução de um projeto florestal depende da disponibilidade de recursos, devendo ainda se nortear por meio de ferramentas de análise econômica, de forma respaldar os investimentos realizados. Segundo o Anuário Estatístico da ABRAF (2013), a importância de financiamentos disponíveis para a alavancagem de novos projetos na área reflete-se no montante de capital inicial necessário, provido através de empréstimos bancários, para a compra de terras, equipamentos, insumos e mudas, construção de infraestrutura, os quais em outras circunstâncias não teriam outros meios de serem viabilizados, senão por tais financiamentos. Além da viabilidade técnica, social, ambiental, os projetos devem necessariamente ser analisados em relação ao aspecto econômico.

Segundo Rezende \& Oliveira (2008), a análise econômica de um investimento envolve o uso de técnicas e critérios de análise que comparam custos e receitas inerentes ao projeto, visando verificar se ele deve ou não ser implementado.

Para Vitale \& Miranda (2010), esse tipo de estudo mostra o quanto os projetos são afetados pela variação da taxa de juros, possibilitando até identificar graficamente uma aproximação que marca a interface entre os intervalos de taxas de juros que determinam viabilidade ou inviabilidade de projetos, ou seja, uma aproximação da TIR.

Sanguino (2009) relata que, atualmente, poucos estudos há sobre investimentos financeiros em projetos de reflorestamentos que contemplem informações sobre custos de implantação, manutenção e comercialização da produção de madeira originada de florestas plantadas.

Assim, este trabalho teve como objetivo promover uma análise econômica de um reflorestamento de eucalipto para fins energéticos pertencente a uma pequena empresa na microrregião de Vitória da Conquista, BA, utilizando como critérios o Valor Presente Líquido, a Taxa Interna de Retorno, o Valor Periódico Equivalente e o Custo Médio de Produção, bem como realizar uma análise de sensibilidade através da variação da taxa anual de juros, do incremento médio anual e do preço da madeira.

\section{MATERIAL E MÉTODOS}

\section{1. Área de estudo}

Os dados foram coletados em uma pequena empresa florestal localizada em um município pertencente à microrregião de Vitória da Conquista, latitude: $14^{\circ} 53^{\prime}$ S; longitude: $40^{\circ} 48^{\prime} \mathrm{W}$; altitude: $876,91 \mathrm{~m}$. A microrregião localiza-se na região sudoeste da Bahia, tem clima semiárido e, segundo a classificação de Köppen, é do tipo Aw, ou seja, clima tropical com estação seca bem definida coincidindo com o inverno, apresentando índice pluviométrico médio anual de $700 \mathrm{~mm}$. 


\subsection{Plantio avaliado}

Analisou-se um plantio florestal de eucalipto com espaçamento de $3 \times 3$ metros, ciclo de corte de 5 anos, destinado à produção de carvão. Foram utilizadas mudas de clones para plantio e replantio. O incremento médio anual do povoamento foi de $35 \mathrm{~m}^{3} / \mathrm{ha} / \mathrm{ano}$, sendo o valor de venda da madeira estimado em 40 reais o metro cúbico.

Todas as operações de implantação foram mecanizadas. Na etapa de condução, houve operações manuais como capinas e roçadas.

\subsection{Critérios de avaliação econômica}

De posse de custos e receitas do reflorestamento avaliado, procedeu-se a uma análise econômica utilizando-se como ferramentas os seguintes critérios: Valor Presente Líquido - VPL, Taxa Interna de Retorno - TIR, Razão Benefício/Custo - RB/C, Valor Periódico Equivalente - VPE e Custo Médio de Produção - CMP.

\subsubsection{Valor Presente Líquido - VPL}

A análise do VPL consiste no valor das receitas menos os custos descontados para o ano zero. VPL positivo indicará viabilidade do projeto, sendo mais atrativo quanto maior for. Valores negativos para o VPL indicarão, portanto, projeto inviável. O Valor Presente Líquido foi calculado utilizando-se a Equação 1:

$$
V P L=R j(1+i)^{-j}-\sum_{j=0}^{n} C j(1+i)^{-j}
$$

\subsubsection{Taxa Interna de Retorno - TIR}

É a taxa de desconto que iguala o valor presente das receitas ao valor presente dos custos, ou seja, iguala o VPL a zero (Silva et al., 2005). Em relação ao critério de viabilidade, o projeto será viável quando a TIR for superior à Taxa Mínima de Atratividade (TMA), conforme a Equação 2:

$$
T I R=R j(1+T I R)^{-j}-\sum_{j=0}^{n} C j(1+T I R)^{-j}
$$

\subsubsection{Razão Benefício/Custo (B/C)}

Constitui critério que estabelece a relação entre o valor atual das receitas e o valor atual dos custos. Essa razão pode ser ilustrada por meio da Equação 3:

$$
R B / C=\frac{\sum_{j=0}^{n} R j(1+i)^{-j}}{\sum_{j=0}^{n} C j(1+i)^{-j}}
$$

De acordo com Rezende \& Oliveira (2008), pode-se dizer que, de forma geral, quando a a razão $\mathrm{B} / \mathrm{C}>1, \mathrm{o}$ VPL é maior que 0 e a TIR é maior que a taxa do projeto.

\subsubsection{Valor Periódico Equivalente Ou Valor Anual Equivalente (VPE ou VAE)}

Esse critério é obtido transformando-se o valor atual do projeto, ou seja, o seu VPL, em fluxo de receitas ou custos periódicos e contínuos, equivalente ao valor atual, durante a vida útil do projeto (Silva et al., 2005). Em se tratando da viabilidade, o projeto será viável quando o VPE for maior que zero, conforme a Equação 4:

$V A E=\frac{V P L\left[(1+i)^{-t}-1\right]}{\left[1-(1+i)^{-n t}\right]}$

\subsubsection{Custo Médio de Produção (CMP)}

Obtém-se dividindo o valor atual do custo pela produção total equivalente (Silva et al., 2005). No que tange ao CMP, o projeto será viável se esse valor for inferior ao valor de mercado da madeira, conforme a Equação 5:

$C M P=\frac{\sum_{j=0}^{n} C j(1+i)^{-j}}{\sum_{j=0}^{n} P T(1+i)^{-j}}$

\subsection{Determinação de custos e receitas}

\subsubsection{Custos}

Em relação aos custos avaliados, considerou-se aqueles referentes às etapas de implantação e manutenção do povoamento florestal. Na etapa de implantação foram contemplados os custos de arrendamento da terra, limpeza da área, controle de pragas, subsolagem, gradagem, plantio, replantio, adubação e irrigação de mudas (Tabela 1). Na etapa de condução foram avaliados os seguintes custos: combate às formigas, custo da terra e custo de capinas e ou roçadas (Tabela 1).

\subsubsection{Receitas}

Após determinação dos custos, realizou-se análise da receita, obtida no quinto ano, após a venda da madeira. Essa foi determinada tomando como base o Incremento Médio Anual (IMA), o número de anos 
Tabela 1. Relação dos custos de reflorestamentos com eucalipto no sudoeste da Bahia.

Table 1. List of the costs of reforestation with eucalyptus in Southwest Bahia.

\begin{tabular}{|c|c|c|c|c|}
\hline Itens de custo & Unidade & Valor unitário & $\begin{array}{l}\text { Quantidade de } \\
\text { insumo }\end{array}$ & Valor (R\$) \\
\hline \multicolumn{5}{|l|}{ 1. INSUMOS } \\
\hline \multicolumn{5}{|l|}{ Fertilizantes } \\
\hline Nitrogênio - N & $\mathrm{Kg}$ & 4 & 20 & 80 \\
\hline Fósforo - P2O5 & $\mathrm{Kg}$ & 3,9 & 30 & 117 \\
\hline Potássio - K2O & $\mathrm{Kg}$ & 2 & 20 & 40 \\
\hline${ }^{\star}$ Formicida $(0 \ldots 5)$ & $\mathrm{Kg}$ & 10 & 11 & 110 \\
\hline Mudas (plantio e replantio) & Ud & 0,36 & 1222 & 439,92 \\
\hline Itens de custo & Unidade & Valor unitário & $\begin{array}{l}\text { Quantidade } \\
\text { de serviço por } \\
\text { unidade }\end{array}$ & Valor (R\$) \\
\hline \multicolumn{5}{|l|}{ 2. SERVIÇOS } \\
\hline${ }^{\star}$ Arrendamento da terra $(0 \ldots 5)$ & ha & 100 & 5 (anos) & 500 \\
\hline Preparo do terreno & $\mathrm{h} / \mathrm{M}$ & 120 & 4 & 480 \\
\hline Adubação na cova & $\mathrm{h} / \mathrm{M}$ & 120 & 0,5 & 60 \\
\hline Plantio e replantio & $\mathrm{d} / \mathrm{H}$ & 45 & 1 & 45 \\
\hline Irrigação & & 450 & 1 & 450 \\
\hline${ }^{\star}$ Combate a formigas $(0 \ldots 5)$ & $\mathrm{d} / \mathrm{H}$ & 80 & 6 & 480 \\
\hline${ }^{* *}$ Adubação de manutenção $(0 \ldots 2)$ & $\mathrm{h} / \mathrm{M}$ & 120 & 3 & 180 \\
\hline${ }^{* * *}$ Capina manual $(0-1)$ & $\mathrm{d} / \mathrm{H}$ & 45 & 2 & 90 \\
\hline ***Roçagem manual $(0-1)$ & $\mathrm{d} / \mathrm{H}$ & 45 & 2 & 90 \\
\hline
\end{tabular}

ha $=$ hectare; $\mathrm{d} / \mathrm{H}=$ dias/homem; $\mathrm{h} / \mathrm{M}=$ horas/máquinas; $\mathrm{Kg}=$ quilograma. ${ }^{*}$ Custos referentes aos anos $0,1,2,3,4$ e $5 .{ }^{* *} \mathrm{Custos}$ referentes aos anos 0,1 e $2 .{ }^{* * *}$ Custos referentes aos anos 0 e 1 .

até a colheita e o preço de venda da madeira no ano de corte $\left(35 \mathrm{~m}^{3} \mathrm{x} 5\right.$ anos $\mathrm{x} 40$ reais).

Os componentes de receita e custos foram descapitalizados de forma a proceder à determinação dos critérios avaliados (Tabela 2).

\subsubsection{Análise de sensibilidade}

Considerou-se como fatores influentes na viabilidade econômica do projeto o preço da madeira, o incremento médio anual (produção) e a taxa anual de juros.

Após análise de viabilidade econômica, procedeu-se a uma análise de sensibilidade para os indicadores VPL, RB/C, VAE e CMP, considerando os três fatores mencionados anteriormente (Tabela 2).

Para a taxa de juros, o índice sensibilidade variou em $2 \%$ para mais e para menos em relação à Taxa Mínima de Atratividade (TMA). Realizou-se, portanto, a análise para taxas de $10 \%, 8 \%$ e $12 \%$, buscando assim retratar possíveis cenários em decorrência da flexibilização da respectiva taxa durante o horizonte de planejamento avaliado, o que poderia ocorrer em virtude da estabilidade ou instabilidade econômica no período. Esses índices são semelhantes aos adotados por
Soares et al. (2003) na análise da viabilidade econômica de reflorestamentos de Eucalyptus grandis para fins de multiprodutos. Esses autores utilizaram para análise de sensibilidade taxas com índices de 6\%, 9\% e 12\%.

Em relação ao preço da madeira, utilizando-se uma variação de 5 reais por metro cúbico, os valores projetados foram 40 reais $/ \mathrm{m}^{3} ; 35$ reais $/ \mathrm{m}^{3}$ e 45 reais $/ \mathrm{m}^{3}$. Tais variações foram baseadas na projeção da cotação de madeira em pé, diâmetro entre $15 \mathrm{~cm}$ e $30 \mathrm{~cm}$, de acordo com o Centro de Inteligência em Florestas, para o ano anterior ao da realização da pesquisa. $\mathrm{O}$ incremento médio anual sofreu variação de $3 \mathrm{~m}^{3} /$ ha para mais e para menos, em relação ao incremento estimado, resultando, portanto, nos seguintes índices: 35,32 e $38 \mathrm{~m}^{3} / \mathrm{ha}$. As oscilações contextualizam cenários de produção florestal possíveis de serem atingidos nas condições edafoclimáticas da região de implantação do plantio.

\section{RESULTADOS E DISCUSSÃO}

Os custos relacionados à implantação e manutenção do projeto avaliado influenciaram diretamente os indicadores analisados. A etapa de implantação 
Tabela 2. Resultado das análises de viabilidade econômica e sensibilidade para um projeto florestal de eucalipto no sudoeste da Bahia.

Table 2. Results of analyzes of economic viability and sensitivity to design a forest of eucalyptus in Southwest Bahia.

\begin{tabular}{|c|c|c|c|c|c|c|}
\hline \multicolumn{7}{|c|}{ ANÁLISE ECONÔMICA } \\
\hline VPL & VPE & $\mathbf{R B} / \mathbf{C}$ & CMP & & TIR & \\
\hline $\mathrm{R} \$ 1.399,24$ & $\mathrm{R} \$ 353,29$ & 1,44 & $R \$ 27,68$ & & $\mathrm{R} \$ 18,5 \%$ & \\
\hline \multicolumn{7}{|c|}{ ANÁLISE DE SENSIBILIDADE } \\
\hline $\begin{array}{c}\text { Taxa de juros } \\
\text { (\%) }\end{array}$ & $\begin{array}{c}\text { Valor da } \\
\text { madeira (R\$) }\end{array}$ & $\begin{array}{c}\text { IMA } \\
\left(\mathbf{m}^{3} / \mathbf{h a}\right)\end{array}$ & VPL (R\$) & VPE (R\$) & $\mathbf{R B} / \mathbf{C}$ & CMP (R\$) \\
\hline 10 & 40 & 32 & 966,69 & 255,01 & 1,32 & 30,26 \\
\hline 10 & 40 & 38 & 1711,79 & 451,57 & 1,56 & 25,49 \\
\hline 10 & 35 & 35 & 795,93 & 209,96 & 1,26 & 27,68 \\
\hline 10 & 35 & 32 & 469,95 & 123,97 & 1,16 & 30,26 \\
\hline 10 & 35 & 38 & 1121,9 & 295,95 & 1,37 & 25,49 \\
\hline 10 & 45 & 35 & 1882,55 & 496,61 & 1,62 & 27,68 \\
\hline 10 & 45 & 32 & 1463,42 & 386,05 & 1,49 & 30,26 \\
\hline 10 & 45 & 38 & 2301,67 & 607,17 & 1,83 & 25,49 \\
\hline 8 & 40 & 35 & 1713,96 & 429,27 & 1,56 & 25,60 \\
\hline 8 & 40 & 32 & 1305,61 & 327,00 & 1,42 & 24,33 \\
\hline 8 & 40 & 38 & 2122,31 & 531,55 & 1,70 & 23,58 \\
\hline 8 & 35 & 35 & 1118,45 & 280,12 & 1,37 & 25,61 \\
\hline 8 & 35 & 32 & 761,15 & 190,63 & 1,25 & 28,01 \\
\hline 8 & 35 & 38 & 1475,76 & 369,61 & 1,48 & 23,58 \\
\hline 8 & 45 & 35 & 2309,47 & 578,42 & 1,76 & 25,61 \\
\hline 8 & 45 & 32 & 1850,08 & 463,36 & 1,61 & 28,01 \\
\hline 8 & 45 & 38 & 2768,87 & 663,48 & 1,91 & 23,58 \\
\hline 12 & 40 & 35 & 1004,47 & 278,63 & 1,34 & 29,88 \\
\hline 12 & 40 & 32 & 664,01 & 184,2 & 1,22 & 32,67 \\
\hline 12 & 40 & 38 & 1344,92 & 373,08 & 1,45 & 27,25 \\
\hline 12 & 35 & 35 & 507,97 & 140,92 & 1,17 & 29,88 \\
\hline 12 & 35 & 32 & 210,07 & 58,28 & 1,07 & 32,67 \\
\hline 12 & 35 & 38 & 805,87 & 223,56 & 1,27 & 27,25 \\
\hline 12 & 45 & 35 & 1500,97 & 416,38 & 1,50 & 29,88 \\
\hline 12 & 45 & 32 & 1117,95 & 310,13 & 1,38 & 32,67 \\
\hline 12 & 45 & 38 & 1883,98 & 522,63 & 1,63 & 27,25 \\
\hline
\end{tabular}

VPL: Valor Presente Líquido; B/C: Razão Benefício/Custo; TIR: Taxa Interna de Retorno; VPE: Valor Periódico Equivalente.

apresentou-se mais onerosa, principalmente devido às atividades de preparo do solo, irrigação, plantio e replantio. A distribuição percentual desses custos encontra-se na Figura 1.

O custo da implantação apresentou um valor total de $\mathrm{R} \$ 2.091,92 /$ ha, referente às atividades de preparo do solo, controle de pragas, obtenção de mudas, adubação, plantio, replantio e irrigação de mudas (Tabela 1). Em se tratando do processo de manutenção, obteve-se um custo de 915,29 reais/ha para o ano zero. Os custos de arrendamento da terra e controle de formigas ocorreram em todos os anos do projeto, já os custos de adubação, capinas e a roçadas, apenas nos dois primeiros anos (Tabela 1).
Os valores arrendamento de terra e preparo do terreno se destacaram, ambos representando $16 \%$ do total dos custos avaliados. Estudos realizados por Silva et al. (2004) confirmam a expressividade do custo de preparo do solo em projetos de reflorestamento. No que se refere ao custo da terra, esse deve ser considerado como custo de oportunidade, entendendo-se que o produtor, mesmo quando titular da terra, deixa de auferir recurso pelo arrendamento em virtude do investimento no próprio negócio. Esses dados estão de acordo com estudos realizados por Silva \& Fontes (2005), os quais contemplaram o valor da terra em projetos de investimento em reflorestamento com eucalipto. 


\section{Distribuição percentual dos custos}

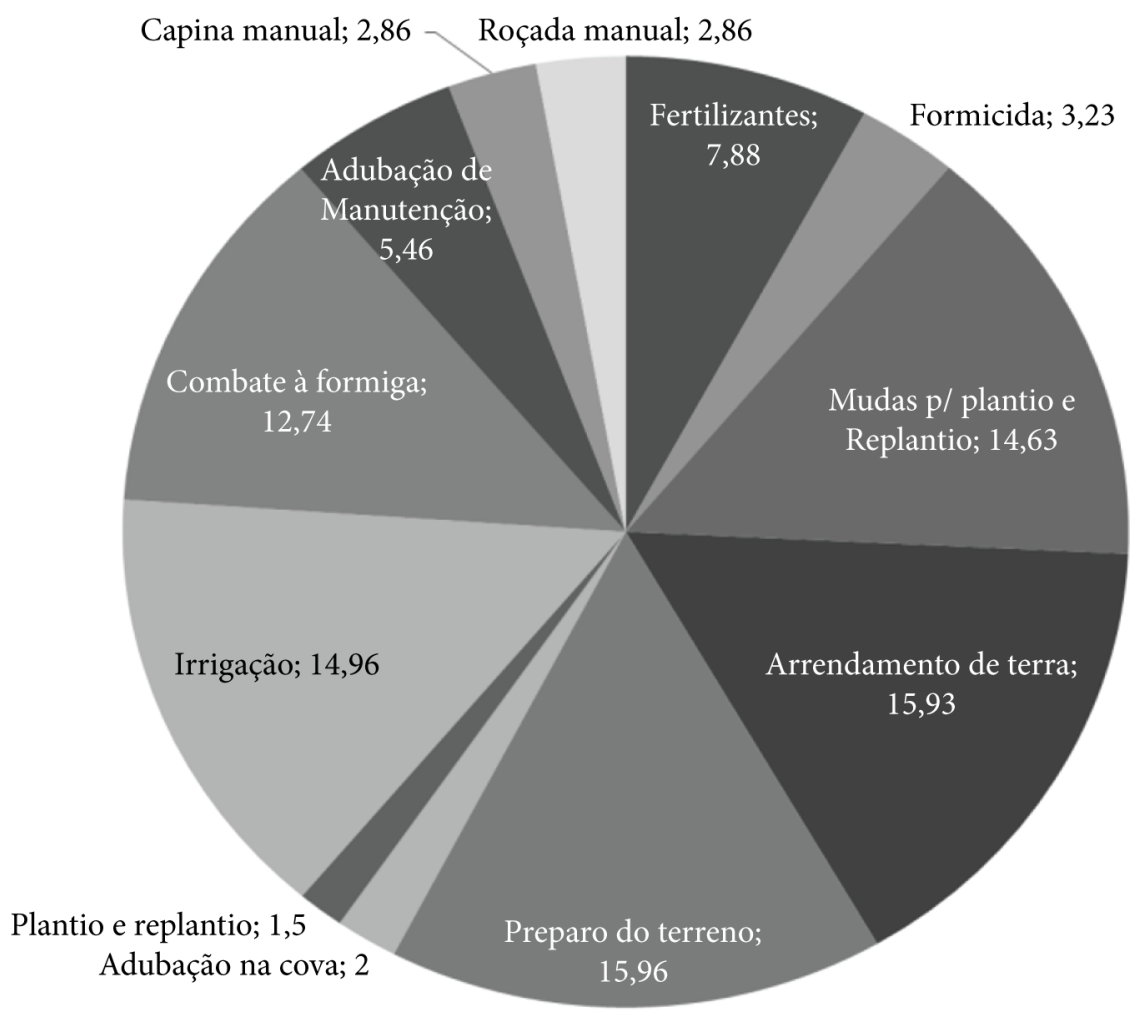

Figura 1. Distribuição percentual dos custos descapitalizados do projeto de reflorestamento no sudoeste da Bahia. Figure 1. Distribution of costs undercapitalized deployment project of reforestation in the South West of Bahia.

A Tabela 2 ilustra a viabilidade econômica para um projeto florestal de eucalipto conduzido para fins energéticos na microrregião de Vitória da Conquista, BA, bem como a projeção de sensibilidade para as variáveis taxa de juros, valor da madeira e incremento médio anual.

\subsection{Análise econômica}

Todas as análises realizadas se mostraram positivas e viáveis em relação aos critérios avaliados. Obteve-se um VPL de R 1.399,24/ha para um horizonte de 5 anos.

Esse resultado, equacionado para uma base anual, proporcionou um valor de $\mathrm{R} \$ 359,29 / \mathrm{ha}$ (VPE), ilustrando de forma mais transparente a rentabilidade para o projeto em questão. A contextualização do VPE apresenta grande importância como parâmetro de comparação entre diferentes projetos de investimento (Silva et al.. 2005).
O custo médio de produção (CMP) mostrou que o projeto foi capaz de gerar lucro da ordem $\mathrm{R} \$ 12,32$ para cada metro cúbico de madeira produzido. Virgens et al. (2015), estudando viabilidade de projetos de reflorestamento de eucaliptos, encontraram lucro de $\mathrm{R} \$ 5,55 / \mathrm{m}^{3}$ em relação ao CMP, evidenciando, portanto, menor lucratividade em relação ao projeto em questão.

A Taxa Interna de Retorno apresentou índice de $18,5 \%$, superando, portanto, a Taxa Mínima de Atratividade considerada no trabalho (10\%). De acordo com Rezende \& Oliveira (2008) e Silva et al. (2005), tal condição respalda a viabilidade do projeto para o indicador em análise.

\subsection{Análise de sensibilidade}

Os resultados configuraram a importância da análise de sensibilidade para as variáveis consideradas. Observou-se que o aumento da taxa de juros em 2\% 
provocou uma diminuição em torno de $22 \%$ no VPL e que sua retração em $2 \%$ proporcionou aumento em torno de $28 \%$ nesse indicador.

Analisando a viabilidade técnica e econômica de projetos de reflorestamento de eucalipto submetidos a regime de desbaste em dois cenários de taxa de juros, Barbosa (2014) obteve um Valor Presente Líquido (VPL) de $\mathrm{R} \$ 446,32 /$ ha, com taxa de juros estimada em $6 \%$ a.a. Para taxa de juros de $8 \%$ a.a., o mesmo autor encontrou um cenário de inviabilidade, com VPL de $\mathrm{R} \$-134,76 /$ ha. Estudos realizados por Soares et al. (2003) e Virgens et al. (2015) mostram tendência de inviabilidade de projetos florestais ante aumento da taxa de juros.

Avaliando retorno econômico de plantios de Eucalyptus grandis em sítios com produtividade elevada e taxa de juros de $6 \%$ a.a., Oliveira et al. (2008) encontraram um VPL médio de $\mathrm{R} \$ 2.493,31 /$ ha para o alto fuste, no espaçamento $3 \times 3$ metros. Embora com a mesma taxa de juros e espaçamento, o VPL encontrado no presente trabalho foi quase $50 \%$ inferior ao relatado na pesquisa em questão. Fatores como índice de sítio e boa adaptação da espécie ao local de plantio podem ter favorecido o IMA, com reflexo na receita e, consequentemente, no valor do VPL.

Bezerra et al. (2011), avaliando reflorestamento com Tectona grandis, encontraram um VPL de R $\$ 1.452,09 / \mathrm{ha}$, utilizando taxa anual de juros de 10\%. Embora tenham encontrado resultado similar ao presente trabalho, o ciclo de corte foi diferente, portanto deve-se considerar uma análise do Valor Periódico Equivalente (VPE), de forma a equacionar o lucro do projeto de acordo com o horizonte de planejamento, conforme relatado por Silva et al. (2005) na associação VPL e VPE.

Em relação ao VPE, aumento na taxa de juros de $2 \%$ diminuiu o valor periódico equivalente em $22,82 \%$, e diminuição da respectiva taxa em $2 \%$ proporcionou um aumento na mesma proporção.

A Razão Benefício/Custo foi bastante sensível, mostrando, para redução na taxa de juros de $2 \%$, elevação de $6,95 \%$. O aumento da taxa em $2 \%$ proporcionou, no entanto, uma retração de 8,33\% para o indicador. A diminuição da taxa em $2 \%$ condicionou ainda redução do Custo Médio de Produção em 7,52\%.

Para a análise de sensibilidade no preço da madeira, foram consideradas as variações de 35 reais, 40 reais e 45 reais. Observou-se que a diminuição dos valores proporcionou retrações dos indicadores, justamente por retratar parâmetros referentes à receita. A variação desse valor não alterou o Custo Médio de Produção, uma vez que o preço da madeira não influencia esse critério, fixado em razão dos custos de implantação e condução e da produtividade equivalente do povoamento.

A sensibilidade também foi projetada para o IMA, utilizando-se nesse caso variações de metros cúbicos por hectare de 32, 35 e 38. A partir dessa análise obtiveram-se, para um menor incremento médio anual (32 $\mathrm{m}^{3} / \mathrm{ha}$ ), os seguintes cenários de sensibilidade: $\mathrm{VPL}=-32,91 \%$; $\mathrm{VPE}=-27,81 \% ; \mathrm{RB} / \mathrm{C}=-8,33 \%$; e CMP $=9,32$. Considerando, contudo, o maior incremento médio anual ( $\left.38 \mathrm{~m}^{3} / \mathrm{ha}\right)$, os critérios foram bastante atrativos: $\mathrm{VPL}=+22,33 \%$; $\mathrm{VPE}=+27,81 \%$; $\mathrm{RB} / \mathrm{C}=+8,33 \%$; e CMP $=-7,91 \%$. Gadelha (2014) salienta que o retorno financeiro pode ser mais atrativo caso sejam introduzidos materiais genéticos mais adaptados às condições climáticas da região, sugerindo desenvolvimento de pesquisas relacionadas ao aumento da produtividade em função da aplicação de técnicas de manejo do povoamento e do solo.

Virgens et al. (2015), na análise de sensibilidade em relação ao IMA e ao preço da madeira, observaram variações de até $60 \%$ no VET e VPL, já para RB/C e CMP, a diferença foi de $11 \%$, índices esses superiores aos do presente trabalho. Tais diferenças podem ser explicadas pela variabilidade dos parâmentos em cada estudo, como, por exemplo, preço da madeira e taxa anual de juros.

Para Rezende et al. (2006), a rentabilidade líquida da floresta depende de fatores oscilantes, como preço, finalidade da produção, produtividade da área, entre outros. Partindo de princípio que a variação da taxa de juros altera a viabilidade dos projetos, a análise de sensibilidade torna-se de grande importância, uma vez que possibilita a avaliação da tendência de viabilidade em relação a um cenário de taxas de juros diferenciadas.

Foram encontrados diferentes cenários para as taxas de juros aplicadas, sendo observado que taxas menores tendem para a viabilidade do projeto. A Figura 2 ilustra a projeção dos valores de VPL em relação às taxas utilizadas na análise de sensibilidade.

Apesar da característica de longo prazo, a atividade florestal avaliada consolidou-se como boa alternativa para pequenos produtores, o que pode ser comprovado pelos cenários de viabilidade econômica em relação 


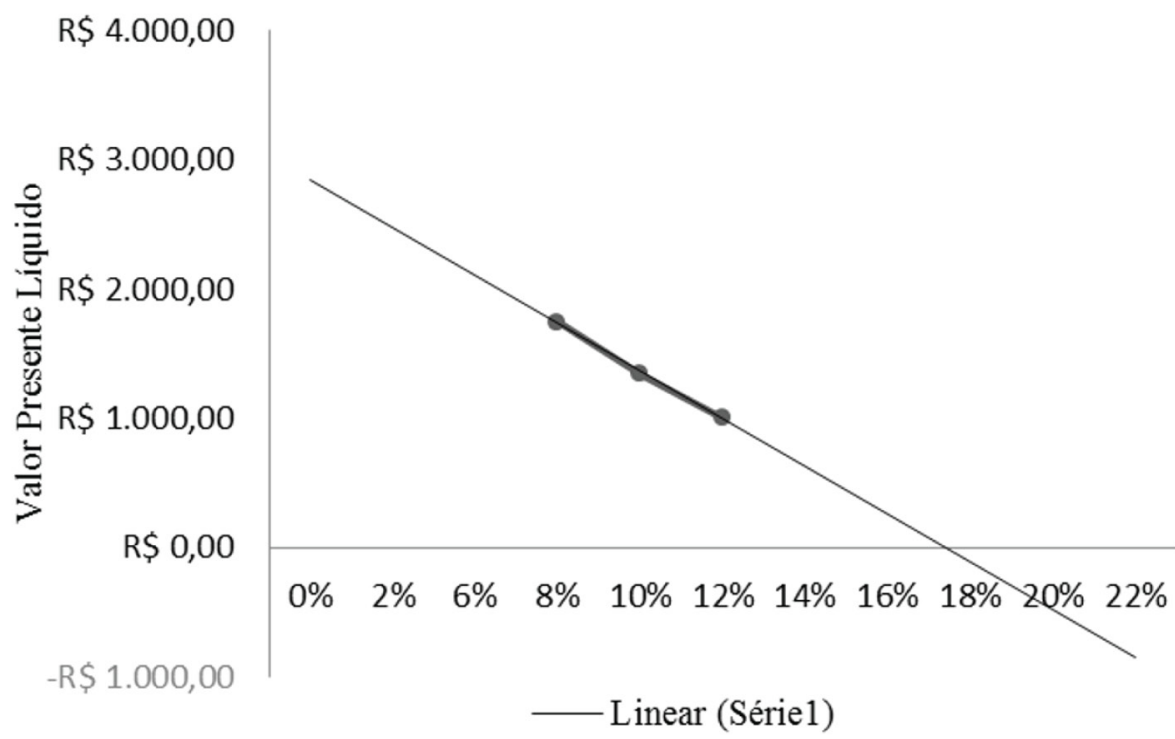

Figura 2. Análise de sensibilidade para o VPL em relação à taxa de juros e determinação da TIR pelo método gráfico. Figure 2. Sensitivity analysis for NPV in relation to interest rate and determination of the TIR by graphical method.

aos critérios avaliados. Cabe ressaltar que a pesquisa constituiu estudo de caso, podendo, portanto, haver variações nos coeficientes de custos e receitas e, consequentemente, alterações nos critérios de viabilidade econômica avaliados. Tal aspecto pode ocorrer em função das diversidades climáticas, edáficas, do tipo do material genético empregado (plantio clonal ou seminal), bem como dos níveis tecnológicos utilizados no processo produtivo.

No contexto da sensibilidade pode-se facilmente respaldar a importância da variação da taxa de juros, cenário perfeitamente possível de ocorrer quando da avaliação de projetos de longo prazo, sobretudo pela instabilidade econômica do país. No que tange às variações no preço da madeira, vários são os fatores influentes, tais como: alterações na oferta e demanda, instabilidade econômica interna ou mesmo uma possível crise global.

\section{CONCLUSÃO}

Para o projeto avaliado observou-se que todos os indicadores mostraram-se viáveis economicamente. O mesmo cenário foi percebido quando da análise de sensibilidade para taxa de juros, Incremento Médio Anual e preço da madeira.

O fato de não se considerar o valor da terra como um custo de oportunidade poderia remeter a uma atenuação de custo e superestimação dos critérios estudados, sobretudo pela sua expressividade no projeto avaliado.

Os resultados da análise econômica e de sensibilidade para os indicadores avaliados mostraram-se ferramenta de planejamento capaz de nortear o pequeno produtor na tomada de decisões quanto ao investimento em projetos de reflorestamento com eucalipto na região.

\section{STATUS DA SUBMISSÃO}

Recebido: 15 jul., 2014

Aceito: 10 jan., 2016

\section{AUTOR(ES) PARA CORRESPONDÊNCIA}

\section{Aline Pereira das Virgens}

Departamento de Fitotecnia e Zootecnia, Universidade Estadual do Sudoeste da Bahia UESB, Estrada do Bem Querer, Km 4, CP 95, CEP 45031-900, Vitória da Conquista, BA, Brasil e-mail: apereira.aline@hotmail.com

\section{REFERÊNCIAS}

Associação Baiana das Empresas de Base Florestal - ABAF. Bahia Florestal Anuário da ABAF 2015: ano base 2014. Bahia: ABAF; 2015. 
Associação Brasileira de Produtores de Florestas Plantadas - ABRAF. Anuário estatístico da ABRAF 2013: ano base 2012. Brasília: ABRAF; 2013.

Barbosa RH. Análise técnica e econômica em um plantio de eucalipto submetido a regime de desbaste [monografia]. Jerônimo Monteiro: Universidade Federal do Espírito Santo; 2014. 26 p.

Bezerra AF, Milagres FR, Silva ML, Leite HG. Análise da viabilidade econômica de povoamentos de Tectona grandis submetidos a desbastes no Mato Grosso. Cerne 2011; 17(4): 583-592. http://dx.doi.org/10.1590/S010477602011000400018 .

Gadelha FHL. Desempenho silvicultural e avaliação econômica de clones híbridos de eucaliptos plantados em diferentes regimes de manejo para fins energéticos [tese]. Carpina: Universidade Federal Rural de Pernambuco; 2014. 147 p.

Indústria Brasileira de Árvores - IBÁ. Relatório IBÁ 2015. Brasília; 2015. 100 p.

Oliveira AD, Ferreira TC, Scolforo JRS, Mello JM, Rezende JLP. Avaliação econômica de plantios de Eucalyptus grandis para a produção de celulose. Cerne 2008; 4: 82-91.

Rezende JLP, Oliveira AD. Análise econômica e social de projetos florestais. 2. ed. Viçosa: UFV; 2008.

Rezende JLP, Padua CTJ, Oliveira AD, Scolforo JRS. Análise econômica de fomento florestal com eucalipto no Estado de Minas Gerais. Cerne 2006; 12(3): 221-231.
Sanguino AC. Custos de implantação e rentabilidade econômica de povoamentos florestais com Teca no Estado do Pará. Ciências Agrárias 2009; (52): 61-78.

Silva KR, Minetti LJ, Fiedler NC, Venturoli F, Machado EGB, Souza AP. Custos e rendimentos operacionais de um plantio de eucalipto em região de cerrado. Revista Árvore 2004; 28(3): 361-366. http://dx.doi.org/10.1590/ S0100-67622004000300006.

Silva ML, Fontes AA. Discussão sobre os critérios de avaliação econômica: valor presente líquido (VPL), valor anual equivalente (VAE) e valor esperado da terra (VET). Revista Árvore 2005; 29(6): 931-936. http://dx.doi. org/10.1590/S0100-67622005000600012.

Silva ML, Jacovine LAG, Valverde SR. Economia florestal. 2. ed. Viçosa: UFV; 2005.

Soares TL, Carvalho RMMA, Vale AB. Avaliação econômica de um povoamento de Eucalyptus grandis destinado a multiprodutos. Revista Árvore 2003; 27(5): 689-694. http://dx.doi.org/10.1590/S0100-67622003000500011.

Virgens AP, Freitas LC, Moreira ACD, Luz DS. Análise econômica e de sensibilidade em projetos de reflorestamentos no Estado da Bahia. Enciclopédia Biosfera 2015; 11: 120-127.

Vitale V, Miranda GM. Análise comparativa da viabilidade econômica de plantios de Pinus Taeda e Eucalyptus dunnii na região centro sul do Paraná. Floresta 2010; 40(3): 469476. http://dx.doi.org/10.5380/rf.v40i3.18908. 